\title{
Prevalence and causes of low vision among schoolchildren in Kibaha District, Tanzania
}

\author{
A.U. KINGO ${ }^{*}$ and B.T. NDAWI ${ }^{2}$ \\ ${ }^{1}$ Ministry of Health and Social Welfare, P.O. Box 9083, Dar es Salaam, Tanzania \\ ${ }^{2}$ Primary Health Care Institute, P.O. Box 235, Iringa, Tanzania
}

\begin{abstract}
Low vision is a major cause of morbidity and has profound effects on the quality of life for many people as it inhibits/reduces mobility and economical well being of the affected individuals and their families. The objective of the study was to determine the magnitude and causes of low vision among primary school children in Kibaha district in Tanzania. Primary schoolchildren were recruited for the study. The inclusion criterion was individual child with low vision of less than $6 / 18$. Visual examination was used for screening the children to identify those with vision less than $6 / 18$. Snellen's chart was used to measure visual acuity of the children with low vision. A total of 400 (6-17 years) schoolchildren were screened. Thirty-eight (9.5\%) had low vision. The prevalence of low vision was statistically higher ( $\mathrm{N}=33 ; 87 \%)$ among $12-17$ years old than among $6-11$ years old $(13 \%)$ $(P<0.05)$. Of the 38 children with low vision, the prevalence in females $(68 \%)$ was statistically higher than in males (32\%). There were multiples causes of low vision among affected children. Congenital anomalies accounted for the largest proportion (65\%) of the causes of low vision. In twenty-three (60\%) of the children (12-17 years), low vision was due to retinopathies. Fifty-five percent of the children with refractive error were aged between 6-11 years. Among the cases, 8 (54\%) had low vision caused by uncorrected refractive errors while the rest $(46 \%)$ were due to other types of refractive errors. Two children had corneal scars; one with central and another with whole corneal scar. In conclusion, prevalence of low vision among schoolchildren in Kibaha district is high and increases with age. The main causes are congenital anomalies. There is need for an early detection of the possible causes and appropriate treatment to reduce the condition among schoolchildren. It is therefore important that the district Council Health Management Team establishes school eye screening programme for early detection and treatment. It is equally important to strengthen advocacy programme targeting schoolchildren, teachers and caregivers on the public health importance of low vision.
\end{abstract}

Key words: low vision, retinopathy, schoolchildren, Tanzania

\section{Introduction}

According to WHO (2005), it is estimated that about 124 million people worldwide are affected or have low vision. More than $90 \%$ of the world's visually impaired people live in developing countries, especially among the rural poor (Thylefors, 1987). The prevalence of blindness and visual impairment has been found to be much higher in the elderly ( $\geq 45$ years). Despite this, low vision among children is also an important public health problem in developing countries (Gilbert et al., 2008). In a study of childhood blindness among 491 pupils in Malawi, Kenya and Uganda, $62.9 \%$ and $14.1 \%$ were blind and severely visually impaired, respectively (Gilbert et al., 1995). In a study in India (Kalikavayi et al., 1997) the prevalence of reported visual impairment and blindness among children aged $<18$ years was $2.5 \%$. The prevalence was significantly lower for children aged less than 6 years $(1.0 \%)$ than for children aged 6-17 years (3.3\%). In the United States, Hispanic children had a significantly higher prevalence of reported visual impairment and blindness are common among children whose families' incomes are low (Frick \& Foster, 2003). In a study to determine the causes of severe visual impairment and blindness in children ( $<16$ years) attending schools for the blind in Kenya, Malawi, Uganda, and Tanzania, 65.2\% were found with severe visual impairment or blindness (Njuguna et al., 2009). Among the major causes of blindness $(<3 / 60)$ include refractive error, trachoma, cataract, glaucoma and age-related macular degeneration (Taylor \& Keefee, 2001).

\footnotetext{
* Correspondence: Amina U. Kingo; E-mail: aminakingo@yahoo.com
} 
Low vision and blindness have been associated with considerable disability and excess mortality; resulting into heavy socioeconomic consequences (Frick \& Foster, 2003). Low vision is recognized as an important problem in the society, but in school children, it can lead to total blindness in later life. There is scanty data that separate the effect of visual impairment or blindness due to refractive error in most of the Sub-Saharan Africa. Poor vision and the inability to read material written on the blackboard can have a serious impact on a child's participation and learning in class and this can adversely affect a child's education, occupation and socio-economic status for life. This study was carried out in the view of the increasing trend of low vision especially in school children and absence of screening programme. The objective of the study was to determine the prevalence and causes of low vision among primary school children in Kibaha District, in Tanzania. Such information is important in planning for prevention of low vision and blindness strategies.

\section{Materials and Methods}

\section{Study area}

The study was conducted in Kibaha District (6-8 $8^{0}$ S, 38.19-39.5 $\left.\mathrm{E}\right)$ in eastern Tanzania. The district has an area of $1,630 \mathrm{sq} \mathrm{km}$, and generally warm, with temperatures ranging between $18.5^{\circ} \mathrm{C}$ to $31.5^{\circ} \mathrm{C}$. It has a population of 132,000 (URT, 2002). Kibaha district has 68 primary schools, out of which 66 are Government, and 2 are private schools.

\section{Study design and sampling}

This was a descriptive cross-sectional study and was carried out from December 2005 to May 2006. All 13,750 primary school children in the district were eligible for the study. The inclusion criterion was individual primary school child with low vision of less than 6/18 in Kibaha district. The sample size of 400 respondents was randomly selected, to cover 8 wards and 10 primary schools. Simple random sampling method was used to select 8 wards, from 15 wards. Before data collection two research assistants were recruited and trained for three days, on data collection.

The proportion was used to get the number of children to be involved in this study in each school. The same procedure was used to get the proportional of children in each class from standard one up to standard seven. Then the representative from each class was selected randomly. In order to get the study units (children with low vision) the children were screened by using observation method and history taking through visual examination. Clinical examinations of the children were performed at respective schools. Screening of school children was done using Snellen's chart to identify those who had vision less than 6/18 through visual examination. Retinoscope was used as a diagnostic tool. Interview administered questionnaires with open and closed-ended questions were used for data collection.

\section{Data analysis}

The collected data was sorted manually and entered into a computer using Excel spreadsheet and then analyzed using EPI Info programme. The WHO categories of visual impairment were adopted to define and analyse vision status for the schoolchildren (WHO, 2004). Low vision was defined as presenting visual acuity of at least $3 / 60$ but less than $6 / 18$ in the better eye.

\section{Ethical consideration}

Prior to conducting the study, permission to conduct the study was sought from District Education Officer. The objectives of the study were explained to teachers and schoolchildren. Those individuals found to be in need of medical intervention were advised and referred to the appropriate services.

\section{Results}

A total of the 400 (6-17 years) schoolchildren were screened for low vision. Thirty-eight $(9.5 \%)$ were observed to have low vision. When retinoscopy and Snellen's chart were compared, the sensitivity and specificity of tests were $100 \%$. The positive predictive value was $63 \%$ while the negative predictive value was $100 \%$. Of the 38 children with low vision, 5 (13\%) were 6-11 years old and $33(87 \%)$ were $12-17$ years old. The difference in prevalence was statistically significant $(P<0.05)$. The prevalence of low vision was significantly higher in females $(68 \%)$ than in males (32\%). Majority $(90 \%)$ of the cases among children in Kibaha district were binocular low vision.

There were multiples causes of low vision among 38 respondents. Congenital anomalies accounted for the largest proportion (65\%) of the causes of low vision. Other specific causes 
were refractive errors $(\mathrm{N}=15 ; 31 \%)$ and corneal scar $(\mathrm{N}=2 ; 4 \%)$. The majority of respondents especially albinos had more than three causes of low vision. Six of the 38 children had low vision due to more than three causes while 5 children had at least two causes. vision in our study participant was higher than that reported from other Sub-Saharan Africa countries (Ezepue, 1997; Abu, 2002; Ngondi et al., 2006). Binocular low vision was common among the schoolchildren.

Study revealed that the age of the

Table 1: Causes of low vision by age group

\begin{tabular}{lllll}
\hline Causes & \multicolumn{3}{c}{ Age group } \\
& $\mathbf{6 - 1 1}$ years & \multicolumn{1}{c}{$\mathbf{1 2 - 1 7}$ years } & \% \\
\hline No. & 5 & \% & No. & 26 \\
Refractive errors & 1 & 55 & 10 & 3 \\
Retinopat scar & 2 & 22 & 11 & 60 \\
Nystagmus & 0 & 0 & 5 & 13 \\
Aphakia & 1 & 11 & 0 & 0 \\
\hline
\end{tabular}

The majority (23) of children with low vision due to retinopathies were aged 12-17 years while the majority (5) with refractive errors were aged between 6-11 years (Table 1). Among the refractive errors cases $8(54 \%)$ of the children had low vision caused by uncorrected refractive errors which was myopic condition. Other types of refractive errors included hyperopia (13\%), and amblyopia (33\%). No child was observed to have astigmatism.

Two children had corneal scars; one with central and another with whole corneal scars. Among the congenital anomalies the majority $(81 \%)$ were due to retinopathies, followed by Nystagmus/albinism (16\%) and aphakia $(3 \%)$. Cataract, strabismus and ptosis were not observed among the screened schoolchildren.

\section{Discussion}

A higher prevalence $(9.5 \%)$ of low vision was observed among school children in Kibaha District. Data from district records also indicate that low vision among schoolchildren in the district is a major health problem. For instance, there has been an increase in the number of patients attending TumbiHospital (Kibaha)from 2002 to 2004; with low vision in schoolchildren accounting for $15 \%-20 \%$. The increasing problem of low vision in the district could be attributed by lack of visual screening and correction measures among schoolchildren. Although the district do implement school health programme (one of the key component of National Health Essential Intervention packages) it does not provide basic eye care services including screening for the causes of low vision. The prevalence of low children contribute to increase on low vision of school children in Kibaha District. Children with the age 6-11years were less affected than those aged 12- 17 years. Older children are more affected probably because as the age increases the problem increases too. Among school-aged children aged 6 to 11 years old, an estimated 5.3 million $(21.5 \%)$ have a vision problem (WHO 2005). Rates continue to rise as children get older, with an estimated $24 \%$ of $12-17$ years olds exhibiting some type of vision problem (WHO, 2003). Similarly, in a study in Hyderabad, India younger subjects ( $\leq 15$ years); myopia was found in $4.4 \%$, hyperopia $59.4 \%$ and astigmatism $6.9 \%$. In adults (>15 years) myopia rose to $19.3 \%$, hyperopia fell to $9.8 \%$, and astigmatism was detected in 12.9\% (Dandona et al., 2002). Like in our study, a higher prevalence of ocular disorders in females than males has also been reported in Nigeria (Ajaiyeoba et al., 2006).

The findings revealed that majority of females children were more affected with low vision than males. Contrary to our findings, in India, the prevalence of visual impairments was higher $(16.9 \%)$ among males than females (12.1\%) (Kalikivayi et al., 1997). Unlike in India where boys are engaged in activities that can cause eye injuries, in Kibaha and other areas of Tanzania girls are engaged in most of the social activities including cooking using firewood. This is likely to cause sour for long time.

The leading cause of low vision among schoolchildren in Kibaha was congenital anomalies; of which retinopathies were the most contributing conditions to low vision. Retinopathies have been reported to be the major causes of low vision and blindness elsewhere 
(Gilbert et al., 2008; Akinsola \& Ajaiyeoba, 2002). The low vision due to retinopathies among our study subjects is likely to have been contributed to high childhood malnutrition and untreated maculopathies. Albinism is also likely to have contributed to the condition. According to Njuguna et al., (2009) the major etiology of visual loss is childhood factor and an estimated $40 \%$ of severe visual impairment and blindness are due to potentially avoidable causes. Visual loss dues to corneal pathology, cataract and retinopathies were the main causes of low vision among children in studies in Malawi, Kenya and Uganda (Gilbert et al., 1995). Similarly, in a recent study among urban population in Nairobi, Kenya, cataract and refractive errors were reported to be the leading causes of visual impairment (Ndegwa et al., 2006).

The study has indicated that the majority of school children with refractive error had myopic condition. A study done in primary schools children in rural Mwanza Region, Tanzania, showed a low prevalence of significant refractive errors. All pupils with significant refractive errors were myopic (Wedner \& Foster, 2000). The results are consistent with the findings elsewhere (Ajaiyeoba et al., 2007). In a previous study in north-western Tanzania a low $(1.0 \%)$ prevalence of refractive error was reported (Wedner \& Foster, 2000). Under corrected refractive error, particularly myopia is especially a problem in school children. Poor vision and the inability to read material written on the blackboard can have a serious impact on a child's participation and learning in class and this can adversely affect a child's education, occupation and socio-economic status for life. If the children and teachers get knowledge to identify children with low vision it will help to reduce the problem among school children.

This study revealed that a corneal scar is a minor cause of low vision among school children in Kibaha District. However in the studies done in Sri Lanka, vitamin A deficiency was responsible for corneal scarring in $19 \%$ of all cases. Other causes of corneal scar included measles, harmful traditional medicines and Ophthalmia neonatorum (Foster, 1996). This shows that presence of intervention on eradication of measles and elimination of Vitamin A deficiency in children made the cases of corneal scars to be few. In Kibaha the problem of Vitamin A is minimal due to availability of food with Vitamin A which is better for the vision. The corneal scar observed in Kibaha was due to trauma and it was only monocular in all cases, there were no corneal scars due to ocular diseases such as trachoma, Vitamin A deficiency or corneal ulcer.

In conclusion, there is a high prevalence of low vision among schoolchildren in Kibaha with females more affected than males. Since most of the causes of low vision are treatable, their early recognition and prompt treatment by regular screening of children would reduce unnecessary visual impairment in Tanzania. It is therefore important that the district Council HealthManagementTeam,includeeyescreening as part of the school health programme. It is also important that districts conduct advocacy and sensitization to schoolchildren, teachers and their parents/guardians, on low vision issues.

Received 22 February 2008

Revised 4 June 2009

Accepted 6 June 2009

\section{References}

Abu, L. (2002) Prevalence and causes of blindness and low vision in Dambatta local government area, Kano State, Nigeria. Nigerian Journal of Medicine 11, 108-112.

Akinsola, F.B. \& Ajaiyeoba, A.I. (2002) Causes of low vision and blindness in a blind school in Lagos, Nigeria. West African Journal of Medicine 2, 63-65.

Ajaiyeoba, A.I., Isawumi, M.A., Adeoye, A.O. \& Oluleye, T.S. (2007) Prevalence and causes of blindness and visual impairment among school children in south-western Nigeria. International Ophthalmology 26, 121-125.

Ajaiyeoba, A.I., Isawumi, M.A., Adeoye, A.O. \& Oluleye, T.S. (2006) Prevalence and causes of eye diseases amongst students in south-western Nigeria. Annals of African Medicine 5, 197-203 .

Dandona, R., Dandona, L., Srinivas, M., Sahare, P., Narsaiah, S., Muñoz, S.R., Pokharel, G.P. \& Ellwein, L.B. (2002) Refractive Error in Children in a Rural Population in India. Investigatie Opthalmology and Visual Science 43, 615-622.

Ezepue, U.F. (1997) Magnitude and causes of blindness and low vision in Anambra State of Nigeria (results of 1992 point prevalence survey). Public Health 111, 305-309.

Foster, A. (1996) Childhood blindness in India and Sri Lanka. Indian Journal of 
Ophthalmology 44, 57-60.

Frick, K.D.\&Foster, A. (2003) Themagnitude and cost of global blindness: an increasing problem that can be alleviated. American Journal of OpthalmologyAmerican Journal of Opthalmology 134, 471-476.

Gilbert, C.E., Ellwein, L.B. \& the Refractive Error Study in Children Study Group (2008) Prevalence and causes of functional low vision in school-age children: results from standardized population surveys in Asia, Africa and Latin America. Investigative Opthalmology \& Visual Science 49, 877-881.

Gilbert, C.E., Wood, M., Waddel, K. \& Foster, A. (1995) Causes of childhood blindness in East Africa: results in 491 pupils attending 17 schools for the blind in Malawi, Kenya and Uganda. Ophthalmic Epidemiology 2, 77-84.

Kalikivayi, V., Naduvilath, T.J., Bansal, A.K. \& Dandona, L. (1997) Visual impairment in school children in Southern India. Indian Journal of Ophthalmology 45,129-134.

Ndengwa, L.K., Karimurio, J., Okelo, R.O. \& Adala, H.S. (2006) Prevalence of visual impairment and blindness in a Nairobi urban population. East African Medical Journal 83, 69-72.

Ngondi, J., Ole-Sempele, F., Onsaringo, A., Matende, I., Baba, S., Reacher, M., Matthews, F., Brayne \& Emerson, P.M. (2006) Prevalence and causes of blindness and low vision in Southern Sudan. PLoS
Medicne 3: e477.

Njuguna, M., Msukwa, G., Shilio, B., Tumwesigye, C., Courtright, P., Lewallen, S. (2009) Causes of severe visual impairment and blindness in children in schools for the blind in Eastern Africa: changes in the last 14 years Ophthalmic Epidemiology 16, 151-155.

Resnikoff, S., Pacolini, D., Mariotti, S.P. \& Pokharel,G.P.(2008)Globalmagnitudeof visual impairmentcaused by uncorrected refractive errors in 2004. Bulletin of the World Health Organization 86, 1-80.

Taylor, H.R. \& Keefeee, J.E. (2001) World blindness: a $21^{\text {st }}$ Century perspective. British Journal of Ophthalmology 85, 261266.

Thylefor, B. (1987) A simplified methodology for the assessment of blindness and its main causes. World Health Statistics Quarterly 40, 129-141.

WHO (2004) Disease of the eye and adnexia. International Statistical Classification of Diseases and Related Health Problems. $10^{\text {th }}$ Revision, Volume 1. Geneba. World Health Organizationa. Pp.426-428.

WHO (2005) Vision 2020 Right to Sight.www. org.com. www.alhusseinrehab.org.jo/ pdf./june2005.

Wedner, S.H. \& Foster, A. (2000) Prevalence of eye diseases in primary school children in a rural area of Tanzania. British Journal of Ophthalmology 84,:1291-1297. 